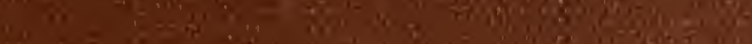

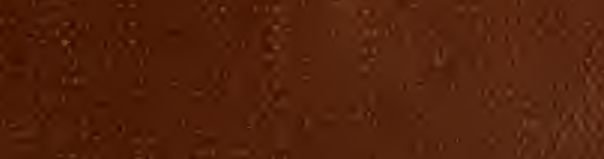

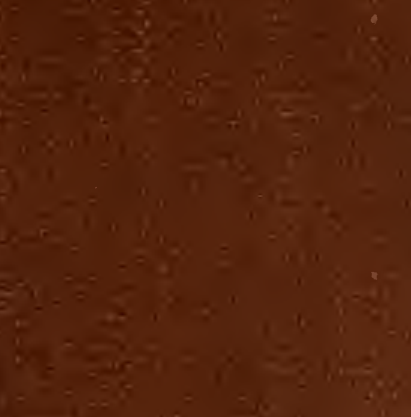

$x=2=0$ ing

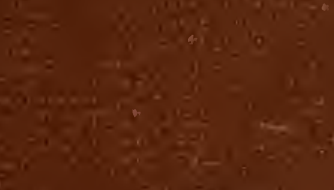

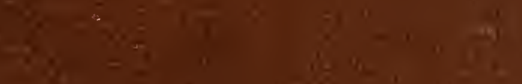

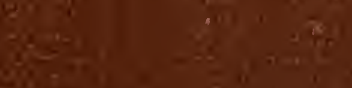

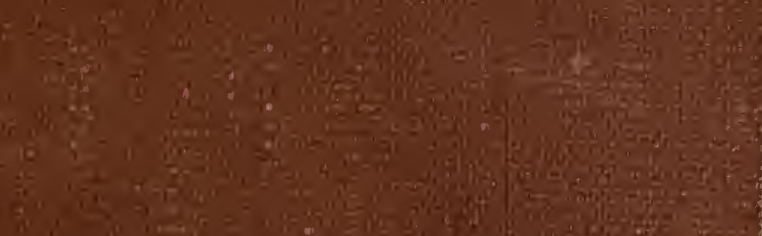

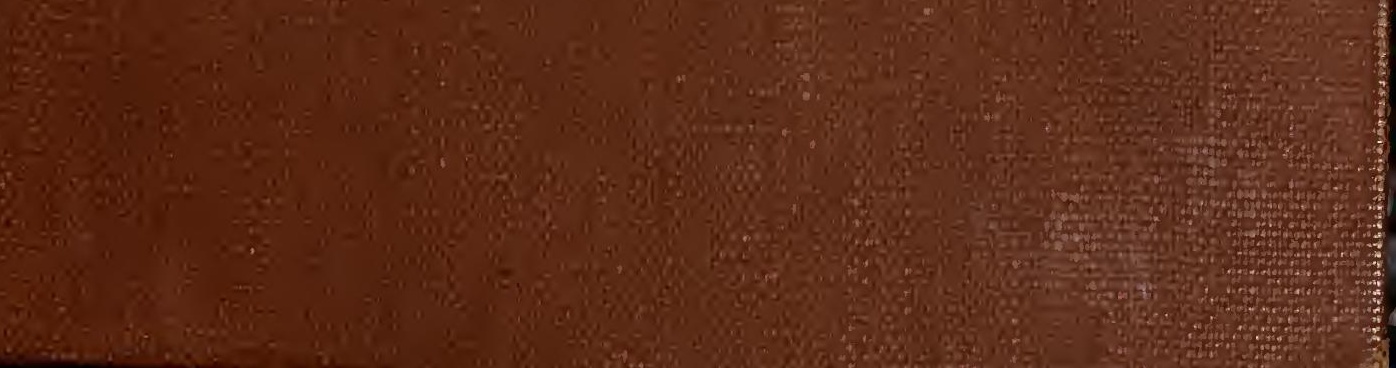




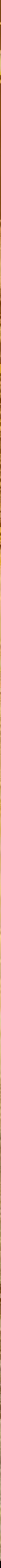




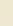




$x=x+2 x+2=$

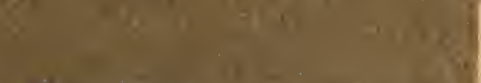

r.

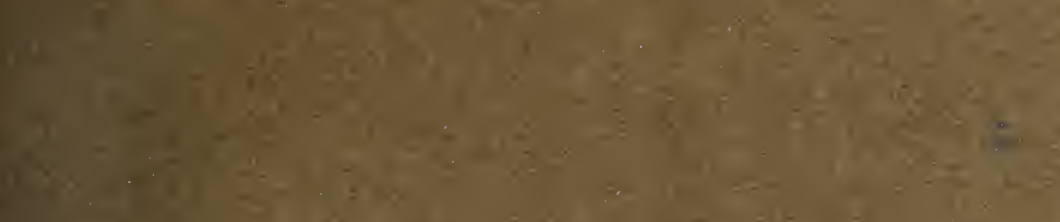

20 


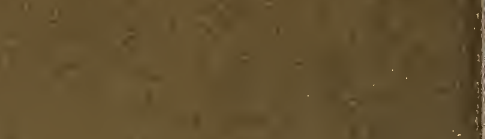




\section{U. S. DEPARTMENT OF COMMERCE \\ R. P. LAMONT, Secretary \\ BUREAU OF STANDARDS \\ GEORGE K. BURGESS, Director}

MISCELLANEOUS PUBLICATION, BUREAU OF STANDARDS, №. 128

\section{A SURVEY \\ OF STORAGE CONDITIONS IN LIBRARIES RELATIVE TO THE PRESERVATION OF RECORDS}

By

ARTHUR E. KIMBERLY

J. F. G. HICKS, jr.

OCTOBER 5, 1931

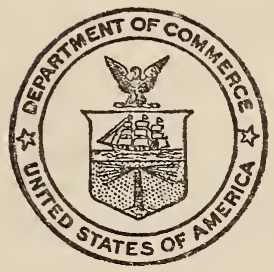

UNITED STATES

GOVERNMENT PRINTING OFFICE

WASHINGTON : 1931 



\title{
A SURVEY OF STORAGE CONDITIONS IN LIBRARIES RELATIVE TO THE PRESERVATION OF RECORDS ${ }^{\prime}$
}

\author{
By Arthur E. Kimberly ${ }^{2}$ and J. F. G. Hicks, jr. ${ }^{2}$
}

\section{ABSTRACT}

A survey of leading present-day libraries was undertaken in order to determine the extent to which conditions of storage may be responsible for the deterioration of records and other material stored in libraries. The inspection stressed particularly conditions within the book stacks relative to the control of temperature, humidity, and air pollution, as well as the exclusion of light, all of which are recognized as important factors.

It was found that while the effects of light and dust were well guarded against in general, no library was able to control completely the variation of temperature and relative humidity within the narrow limits considered necessary for successful preservation of records and none attempted to minimize acidic pollutions of the air.

In view of the conditions found, as a result of this survey, and of corroborating laboratory experiments, optimum conditions of air purity, temperature, and illumination considered desirable for preservation of records were formulated, and means of obtaining them suggested.

\section{CONTENTS}

Page

I. External deteriorating agents

II. Method of inspection

III. Results

IV. Discussion of results.

V. Recommendations

VI. Summary

VII. Acknowledgment

\section{EXTERNAL DETERIORATING AGENTS}

The permanence of paper is affected by two distinct groups of factors-one, the "internal" agents of deterioration or those substances produced or left within the paper by the method of manufacture; the other, the "external" agents of deterioration or the factors which are introduced by the conditions of use and storage of the finished paper. In order, therefore, to obtain some indication of the extent to which these external agents are responsible for the deterioration of books stored in libraries, a survey of storage conditions in present-day libraries was undertaken.

The preliminary step in such a survey was the definition of the external agents as set forth by the literature. As early as 1881, Girard ${ }^{3}$ pointed out that cellulose, the principal constituent of paper,

1 This is one of a series of investigations concerning the preservation of written and printed records, which is being made at the National Bureau of Standards with the assistance of a fund granted for the purpose by the Carnegie Corporation to the National Research Council.

2 Research associate, National Research Council.

A. Girard, Ann. chim. phys., [5] 24, p. $337 ; 1881$. 
is readily attacked by acids and that the resulting product is further degenerated by contact with air. Later workers ${ }^{45}$ confirmed his statements and indicated other important factors in the deterioration of paper. Further perusal of the literature shows the following external agents to be of consequence in any consideration of paper preservation.

1. Light, ${ }^{6} 7891011$ particularly sunlight, attacks both the paper fibers and the sizing material, producing "yellowing" and brittling.

2. The adsorption of moisture containing sulphurous and sulphuric acids resulting from the combustion of coal and other present-day fuels, produces marked deterioration..$^{12} 131415$

3. Successive changes in atmospheric temperature and relative humidity seem to exert a marked deteriorative effect, ${ }^{1617}$ the phenomenon most frequently observed being that of brittling following prolonged storage in warm, dry places.

4. Insects, worms, molds, and fungi also attack books in some instances. ${ }^{18} 192021$

Since the literature indicates that the above factors influence paper preservation, it follows that the ideal library for the preservation of records would be one in which it is possible to control or eliminate the "external" deteriorating agents, and it was to this ideal library that the institutions investigated were compared.

\section{METHOD OF INSPECTION}

Whenever possible the library in question was visited in order to discuss with the staff the general problem of paper preservation, as well as any difficulties peculiar to the individual library. Following this conference, a general tour of the library building was undertaken, particular stress being laid upon inspection of every phase of illumination and ventilation, including heating. The condition of the stored material and of the air surrounding it was also carefully noted. In the event that a visit proved to be impossible, the information desired was obtained as far as possible by correspondence.

\section{RESULTS}

The results of the inspection of 13 libraries suggested by the New York Public Library are given in Table 1. The institutions included in the survey are located in the United States from the Atlantic coast to the Pacific coast and comprise both urban and country libraries.

4 W. Herzberg, mitt, kgl. Materialprüfungsamt, Berlin Lichterfelde West., Jahrg. 25, pp. 116-119; 1907 .

5 Aribert \& Bouvier, La Papeterie, 42, pp. 338-352 ; 386-392 ; 1920.

6 V. Schoeller, Wochbl. Papierfabr., 43, p. 3222 et seq. ; (serial) 1912.

7 P. Klemm, Papier Zt., 27, pp. 961-963; 1902.

8 C. Schwalbe, Wochbl. Papierfabr., 38, pp. 1472-1473; 1907.

$\checkmark$ B. Haas, Papierfabr., 12 pp. 891 and $919 ; 1914$.

10 A. B. Hitchins, Paper, 22, pp. 11-15; 1928 .

11 Kimberly and Hicks, B. S. Jour. Research, 6 (R. P. 307), May, 1931.

12 Des Voeux \& Owens, The Lancet, p. 47; Jan. 16, 1912.

13 U. S. Bureau of Mines Bulletin No. $98 ; 1915$.

14 Mellon Institute, bulletins on smoke abatement (10 in all).

15 Report, Chicago Assoc. Commerce, Smoke Abatement; 1915.

16 O. Braums, Pulp Paper Mag. Can., 26, pp. 11, 165; 1928.

17 J. Norris, Library J., 38, p. 16; 1913.

18 W. R. Reinick, Am. J. Phar., 83, p. 503 ; 1911.

19 See Pierre, Compt. Rend., 164, p. $230 ; 1917$.

20 V. Galippe, Compt. Rend., 169, p. 814 ; 1919.

21 Arturo Scarone, El libro y sus enemigos, Montevideo, 217 pp. $8^{\circ} ; 1917$. 


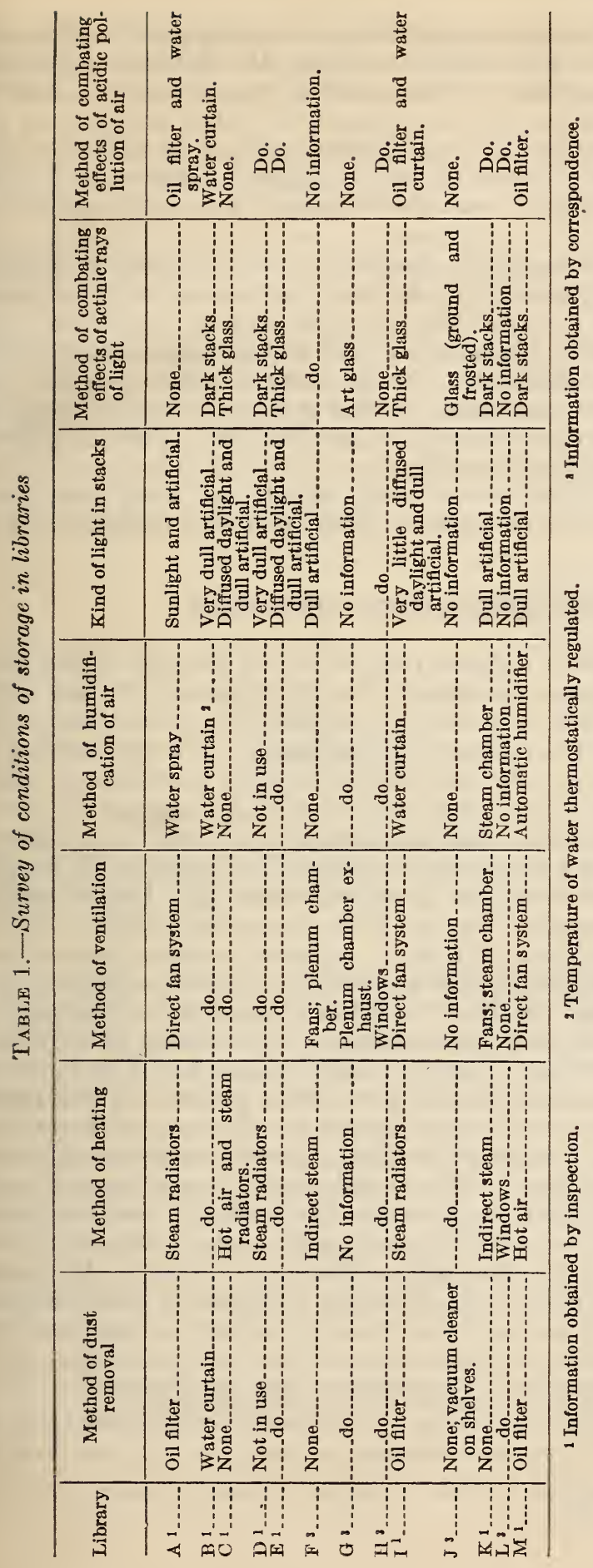


In addition to the information obtained concerning air, light, and. temperature control in the libraries visited, the following general observations of the condition of the material stored in these institutions were made, namely:

"Yellowing" was observed in hot, dry, and dusty places in the path of direct sunlight. Books stored in diffused light seemed to be little affected. "Brittling" was also observed under the same circumstances.

Dusty papers were frequently observed to be discolored and quite often brittle, but no general rule for the correlation of these facts could be formulated.

No damp places were observed at the time of this survey, but several spots were pointed out as being damp at other seasons. In these places, the papers examined seemed soft and "fuzzy," bearing a white powder which could readily be brushed off. They also show brown splotches known as "foxing."

Apparently, little difficulty was being experienced with pests, as is to be expected with the precautions taken to insure cleanliness and good ventilation.

\section{DISCUSSION OF RESULTS}

An inspection of Table 1 shows that of the 13 libraries listed only 4 possessed the equipment necessary for the removal of dust from the incoming air of their ventilating systems. Oil filters were used in 3 of the 4 libraries attempting dust removal. The elimination of dust from library air is very important, for dust particles, in addition to their abrasive action upon the paper and bindings of stored material, act as nuclei for the condensation of acidic moisture.2. Every library inspected attempted to reduce the amount of dust in the stacks and on the books by systematic dusting. In several instances small hand vacuum cleaners were extensively used.

If air containing sulphur dioxide is allowed to come into contact with cotton fabric, sulphuric acid is formed upon the surface of the substance. ${ }^{23}$ A similar reaction would be expected in the case of papers, since both substances are composed essentially of cellulose. This acid is not volatile at ordinary temperatures and, hence, exerts a cumulative effect throughout the life of the paper. If the paper contains iron, as most commercial papers do, the rate of formation of sulphuric acid from sulphur dioxide is greatly accelerated by the catalytic effect of the iron. ${ }^{2425} 26$ if this acid is once formed upon the sheet, its concentration varies with the moisture content (relative humidity) of the surrounding atmosphere, the acid acting as a dehydrator in a very dry atmosphere, literally burning the paper, while in a moist atmosphere it functions as an agent of acidic hydrolysis. The problem of air pollution is most serious as indicated by

22 Osborn Monnett, Smoke Abatement, U. S. Bureau of Mines Bull. No. 273.

23 John B. Wilkie, U. S. Bureau of Standards, Research Paper No. 294.

24 S. F. Cooke, Rôle of Certain Metallic Ions as Oxidation Catalysts, J. Biol. Chem., 10, pp. $289-312 ; 1926$.

20 L. P. Wilson, Catalytic Action in the Oxidation of Cellulose, J. Soc. Chem. Ind., 39, p. $177 \mathrm{~T} ; 1920$.

20 . Baudisch and D. Davidson, Catalytic Oxidation by Means of Complex Iron Salts, J. Biol. Chem., 11, p. 501; 1927. 
Table 2, which shows the precipitation of sulphuric acid in tons per square mile per year in several European and American cities. A further illustration of the quantity of sulphur dioxide present in the atmosphere is the fact that the sulphur content (determined as $\mathrm{SO}_{3}$ ) of filter oil used in a New York public library increases about 100 per cent over the original value of 0.46 per cent $\mathrm{SO}_{3}$ during three weeks' use in an oil filter. When one considers that oil filters are very inefficient as a means of removing acidic pollutants from the air this increase assumes a position of paramount importance as an index of conditions already at hand. Every indication of the situation at present points toward increasingly polluted urban atmospheres and in consequence an increased effect unless immediate steps are taken to minimize the amount of polluted air in libraries and similar institutions. It is believed that such a minimization could be effected by the substitution of a mildly alkaline solution for the water now used in humidifying and purifying library air.

TABLE 2.-Precipitation of sulphurio acid in cities

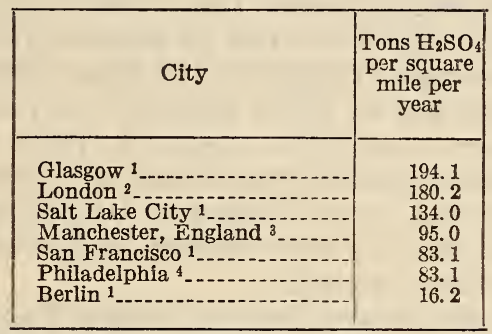

1 Osborn Monnett, G. St. J. Parrott, H. W. Clark, Smoke Abatement Investigation at Salt Lake City, Utah, U. S. Bureau of Mines Bulletin No. 254.

2 Des Voux and Owens, The Sootfall of London, The Lancet, p. 47; Jan. 6, 1912.

8 Recent Progress in Smoke Abatement and Fuel Technology in Manchester, Mellon Institute, Smoke Investigation Bulletin No. 10.

Data from University of Pennsylvania.

Six of the thirteen libraries included in this survey possessed machinery for humidity control, but in two cases the apparatus was not in use at all, and in a third instance the plant was effective only in cool weather owing to the lack of a refrigerator. An attempt was made, several years ago, to use the third-mentioned plant in the summer, but when the advent of a spell of cooler weather precipitated the moisture from the air in the stacks upon the books stored therein, resulting in extensive damage from molding, the attempt was abandoned. All of the equipment in full-time use was of the water-curtain type with no means of regulating the temperature of the water save in one instance where modern thermostatic control had just been installed. The average library using average equipment can not control the humidity of the air within its stacks very closely. Table 3 shows the variation of humidity in an institution which uses oil filters and a water spray for purifying and humidifying the incoming air. 
TABIA 3.-Variation of relative humidity within a library

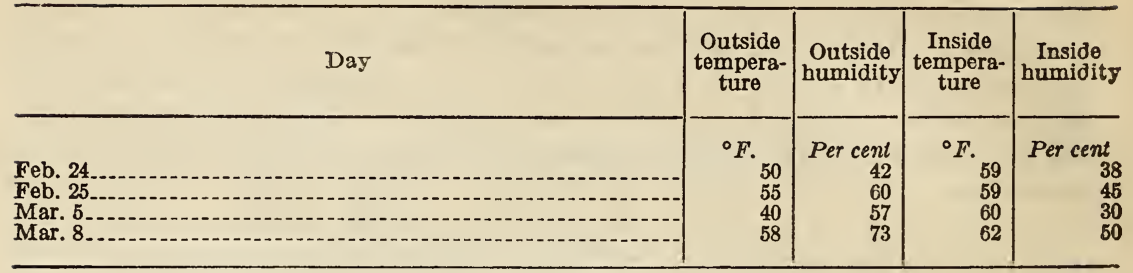

Inspection of Table 3 shows a pronounced fluctuation of relative humidity in this case, the lower limit of moisture content being below that considered desirable for the successful preservation of stored records. None of the libraries inspected made a definite attempt to reduce acidic pollution of the air, but those using oil filters and water curtains reduced the acidity materially during the process of air treatment for other purposes.

The situation regarding the protection of books from the action of daylight is considerably better than that dealing with the other phases of protection, for 10 of the 13 selected libraries minimize the effect of the actinic rays of light by the total elimination of windows in 3 cases, or by the use of thick glass in the remaining 7 examples. In only one instance is sunlight admitted freely to the stacks, and it may be noted that excessive deterioration is apparent in this case. Book stacks, in general, were found to be lighted by small, frosted incandescent bulbs which were switched on and off as required. This is a very commendable practice.

The results of the survey having shown the conditions which a book stored in an average library would encounter, a series of laboratory experiments was initiated to determine the extent of the effect of each individual "external" agent of paper deterioration and to ascertain means of minimizing its action.

Rosin and other materials used in the rosin sizing of paper have been subjected to the action of light with the result that all varieties of rosin, both bleached and unbleached, were found to be light sensitive, darkening in color under the influence of light..27 The presence of ferrous iron was found to accelerate this color change materially. This is additional evidence that rosin sizing, as currently applied, is one cause of the yellowing of records with age. Furthermore, unpublished results obtained at the bureau by Rasch indicate that direct exposure of various types of record papers to sunlight, for a period of only 100 hours on each side, decreased their folding endurance from 25 to 63 per cent of the original. Both of these findings serve to emphasize the necessity of protecting records from the destructive effects of daylight. An investigation of the effect of air polluted with 5 to 10 parts sulphur dioxide per $1,000,000$ on the various types of record papers is in progress, and results already obtained show that 10 days' exposure to such a polluted atmosphere causes losses in physical strength running as high as 40 percent and increases in acidity ranging from 90 to 400 per cent. If so short an exposure as 10 days will produce an effect of

${ }^{27}$ See footnote 11, p. 2. 
this magnitude, one may well wonder that publications have survived as well as they have, and considering the constantly increasing acid pollution of the air, a long further life is problematic.

\section{RECOMMENDATIONS}

Taking into account present library conditions and the results of the laboratory work to date, the following recommendations as to library conditions may be made:

1. Daylight, particularly the actinic rays, should be rigorously excluded from bookstacks, either by the total elimination of windows or so far as possible by the use of thick glass. Any necessary illumination should be supplied by small, frosted, incandescent lamps, lighted as required.

2. Temperature and humidity should be automatically regulated within relatively narrow limits. A suggested range for temperature is $65^{\circ}$ to $75^{\circ} \mathrm{F}$., and for humidity, 45 to 55 per cent.

3. Incoming air should be purified to remove dust (oil filters) and acidic pollutants (alkaline-water wash in scrubbers).

4. When books or other records are stored in a purified atmosphere they should not be removed from it unnecessarily, as a short exposure to impure air may undo the preservative measures of many years' duration.

The machinery necessary to carry out recommendations 2 and 3 would be:

1. Oil filters of a type in which the oil coating is continually renewed.

2. Refrigerating apparatus to cool both incoming air (when necessary) and the solutions for the water curtains.

3. Water curtains, utilizing slightly alkaline solutions and having thermostatic control of temperature.

4. Apparatus to heat to desired temperature purified, cold air coming from water curtain.

In connection with air conditioning it is obvious that the installation and operation of costly apparatus is useless if members of the library staff and others are permitted to open windows, thereby allowing impure outside air free access to the library building. Some difficulty of this nature may be encountered at the outset, but if the operating conditions chosen are conducive to increased comfort, and it is believed that such is the case with the recommended conditions, these troubles should soon disappear. Conditioned air is coming to be used more extensively every day, not only in places of amusement but also in industrial plants and office buildings, with increased. comfort and efficiency to all concerned.

\section{SUMMARY}

1. Daylight, polluted air, variation of temperature and humidity, and pests, are "external" agents of paper deterioration.

2. The effects of light are well recognized and guarded against in most libraries, although one library, ultramodern in most respects, is without protection against light. 
